\title{
Exercising Agency
}

\author{
Survivors' Support Groups
}

It was about seven p.m. and the sun had just set as Okwera-whose case study narrative opened this book - and I sat by the pool and shared a cold Anchor beer at a small boutique hotel in Cambodia's capital, Phnom Penh. We talked about the tiring journey he had taken from Uganda to Cambodia and the jetlag he experienced for the first time ever in his life. We then moved on to mostly discuss different farming strategies-a topic I admittedly had (and continue to have) very little knowledge of, much to Okwera's amusement. We were both in the country for the 2015 South-South Institute (SSI) on Sexual Violence against Men and Boys, joined by numerous male survivors of sexual violence as well as practitioners and activists from around the globe, including several colleagues from the Refugee Law Project (RLP), who co-organized this groundbreaking event.

Earlier that week, Okwera had shared with the institute's participants his experience of forming the Men of Courage survivors' support group that he coordinates as the chairperson. The day thereafter he gave an incredibly inspirational and motivational speech as part of the closing ceremony of the institute, which included excerpts of the testimony opening this book. As part of our conversation about farming strategies, Okwera explained to me how group members engage in collective agricultural activities, and that this helps them to jointly generate an income to support themselves and their families-something that many survivors up to that point struggled with on their own, because of the numerous injuries and health complications as a result of the sexual violations, as explored in the previous chapter. "The group is so important because it allows every one of us to be free and to support one another," he elaborated further. "It also helps us to better understand what has happened to us, and to find solutions for how to move forward," he added. The institute in Cambodia was indeed a perfect stage to reflect on the transformative and agentive potential of the group, which over 
the years has empowered Okwera to be where he was and to advocate for male survivors' needs.

When I returned to northern Uganda about half a year later, for the longer spell of my field research and had a chance to engage with the Men of Courage group more closely and regularly, almost all of its members on different occasions agreed with Okwera's views about the group. They all explained how the group "has helped us come together and be one," and how their activities "make people aware about the violations and suffering we had undergone so many years ago." For the survivors I engaged with, the group was therefore an important piece in a broader and procedural puzzle of engaging with their experiences, by way of coming to terms with their gendered harms. In light of this, in this chapter I focus on the Men of Courage survivors' group as an important avenue for survivors to exercise agency.

This analysis thereby reveals that despite being confronted with a myriad of gendered harms and vulnerabilities (chapter 4), male survivors over time also actively engage with their harmful experiences in a number of ways, and by exercising differing forms of political agency. In the literature, however, sexual violence against men is almost exclusively portrayed through the frame of vulnerabilities, representing male survivors as ever-vulnerable victims without a voice and without any agency, and as indefinitely stripped off their manhood. In this chapter, I seek to refute these essentialist portrayals, by outlining how survivors exercise different politicized strategies and choices in order to come to terms with their experiences in different ways. Although I take into account different instances of survivors' agency, such as strategically navigating silence and disclosure, I specifically set the focus on one particular avenue for survivors to exercise agency and engage with their experiences: The example of male survivors' support groups, and in particular the Men of Courage survivor association in northern Uganda. In response to the gendered impact of wartime rape, and in the absence of formalized support avenues, numerous male survivors across the conflict-affected territory began creating their own spaces to advocate for their needs, in the form of survivors' support groups.

Founded in 2013 and exclusively composed of and led by Acholi male sexual violence survivors, the Men of Courage group offers an avenue for them to collectively respond to their sexual and gendered harms. In this association, male survivors exercise agency in ways such as these: by engaging in joint agricultural activities, thereby providing an income for them and their families; by organizing storytelling sessions among members of the groups, thereby collectively making sense of their harmful experiences and their contemporary challenges; and by carrying out national and international advocacy work on sexual violence against men, thereby seeking recognition of their otherwise silenced and marginalized experiences. Essentially, such an examination of agency challenges the static and essentialist ways in which sexual violence survivors are commonly portrayed as 
exclusively passive, vulnerable, and helpless, instead showing that survivors can act as active agents in their quests to respond to their suffering and harms.

This chapter proceeds with a brief examination of the ways in which crimes of sexual violence against men in general and male survivors' lived realities are commonly portrayed, in essentialist and infantilizing ways, depicting male survivors as ever-vulnerable victims in need of protection, rather than as potentially agentive subjects. In doing so, I draw on feminist IR scholarship that in recent years has brought increased attention to women's and girls' agency in times of war and postconflict settings. I then offer a brief attempt to theorize the understanding of political agency that underpins my analysis, before proceeding with an empirically grounded overview of the role of victims' associations in postconflict northern Uganda in general, and an introduction of the Men of Courage support group specifically. The analytical core of the chapter then homes in on the ways in which survivors exercise agency, primarily in the context of support groups, but also in many other ways, for instance by navigating "engaged silences." I round off the chapter with an examination of how through this agentive capacity, groups simultaneously create pathways to justice on the microlevel, thereby linking this chapter with the next.

\section{SEXUAL VIOLENCE, VICTIMHOOD, AND AGENCY}

Despite the prevailing marginalization of male-directed sexual violence throughout scholarship and praxis, important political, empirical, and conceptual inroads have been made into recognizing men and boys as victims and survivors of wartime sexual violence. As the overview in chapter 2 shows, most studies argue that sexual violence against men is employed strategically and systematically, often portrayed and framed in the "rape as a weapon of war" narrative (Eriksson Baaz and Stern 2013), aimed at terrorizing, punishing, intimidating, and humiliating its victims. Emerging scholarship has also begun to examine the manifold vulnerabilities and harms experienced by male sexual violence survivors, and different studies, complemented by the previous chapter in this book, have focused on the gendered consequences of sexual violence.

However, as per this focus, crimes of male-directed sexual violence and survivors' experiences have thus far almost exclusively been analyzed with attention to, and through the frames of, vulnerabilities. As a result, existing studies-whether willingly or unwillingly - fall into a tendency to represent "survivors as victims without a voice," resulting in a victimizing and "disempowering narrative of silenced, isolated, and wholly marginalized male survivors" (Edström and Dolan 2018: 176) indefinitely stripped of their masculine identities and without any agency. Even though agency is considered a masculine trait, male survivors-who are believed to be robbed of their masculinity as a result of sexual violenceby association are also seen as deprived of their agency. But, as argued by Baines, 
"one's vulnerability in one relationship does not define the person as ever vulnerable" (Baines 2017: 14), as I seek to further illustrate throughout this chapter.

Thus far, however, how in spite of their manifold vulnerabilities, male survivors also actively engage with their experiences and exercise myriad forms of agency has not yet been analyzed. This in turn results in incomplete and essentialist scholarly representations of the dynamics of wartime sexual violence in general, and of male survivors' lived realities in particular. Potential forms of agency in this context can include navigating the silence surrounding one's marginalized experience or the choice of joining (or not joining) and engaging in a survivors' support group.

In the context of a move toward a more global international relations (IR) (Acharya 2014) and growing attention to peacebuilding "from below" and at the local level, different studies increasingly emphasize the importance of recognizing conflict-affected communities' agency, to facilitate more sustainable peace, to challenge (neo)colonial representations of international politics, and to construct more holistic analyses of the lived realities within armed conflicts. Focusing on victims' and local agency during wars comes at a poignant moment, as questions around victimhood, culpability, and responsibilities have been subjected to increasing scrutiny in the growing literature on conflict studies. Indeed, the existing bodies of literature frequently fall into a (wrongful) tendency to construct an "ideal" type of victim, as a person without agency and as ever-vulnerable, visà-vis a perpetrator whose unrestricted agency must be brought under control. In addition to reinforcing a dichotomous victim-perpetrator binary, these assumptions produce essentialist representations of victimhood and survivorhood. Specifically, such portrayals reduce victims as apolitical subjects in need of external (and mostly white, masculine, and patriarchal) protection, rather than as political actors with the potential to analyze, engage with, and respond to their harms on their own terms.

Yet growing evidence shows that conflict-affected populaces are not merely passively subjected to violence and war; instead they actively resist, cope, survive, display remarkable resilience, and "strive to create a meaningful world in the midst of chaos" (Bolten 2014: 21; see Das 2007). Indeed, recent years have witnessed increasing "interest in the political agency of human beings whose agency is often seen to fall outside the realm of politics, or whose political roles and actions are considered when prompted by contingencies such as war or social unrest" (Häkli and Kallio 2013: 182).

With some exceptions, however, much of this research is narrowly focused on resistance, resilience, and survival, but does not fully comprehend the manifold ways in which conflict-affected populaces and communities position themselves as political actors and execute a variety of politicized choices and acts, often in quotidian and mundane ways - a gap that the examination here seeks to address, but that also warrants further research. For instance, in Sri Lanka, Walker (2010) 
discusses the agency of vulnerable populations, exercised in subtle and quotidian ways. Anthropologist Carolyn Nordstrom (1997) further shows that civilians in war-torn Mozambique in myriad terms endeavored to keep life as "normal" as possible, while political scientist Koloma Beck (2013) examines how civilian populations in Angola enforced and reassured the "normality" of civil war. Focused on northern Uganda, Sverker Finnström (2008) unpacks the manifold ways in which individuals seek to deal with the physical, psychological, social, and moral destruction of a protracted war, primarily by way of reasserting their ties to the spiritual realm.

At the same time, constructions of responsibility, victimhood, and agency during times of war are also heavily gendered, frequently based upon dichotomous constructions of male perpetrators and female victims. In her groundbreaking analysis of the gender politics of militarism, Cynthia Enloe (2004) critically exposed these essentialist binary categorizations of "all the men are in the militias and all the women are victims." All too often, this (re)produces an unreconstructed view of men as universal aggressors and women as universal victims during armed conflict. In addition to ignoring masculine vulnerabilities in conflict settings-including the widespread empirical reality of sexual violence against men-such prevalent assumptions fail to explain for women's roles in conflict, and they obscure female agency during and after war.

As noted by Erin Baines, however, the study of gender-based violence "would do well to incorporate a conceptualization of victim agency, and to avoid reducing men's and women's experiences of sexual and gender-based violence to acts solely done to them" (2015: 320). Seeking to dismantle these essentialist views, and guided by feminist curiosity to challenge the hetero-patriarchal manifestations of gender violence, scholars across disciplines-but in particular in anthropology and feminist IR-have attempted to "collapse the often gendered opposition of agency and victimhood that typically characterizes the analysis of women's coping strategies in war zones" (Utas 2005: 403). In light of this, different studies have begun to complicate gendered notions of victimhood and to bring attention to women's agency, focusing on how women and girls resist, subvert, and navigate the opportunities and constraints that characterize their everyday lived realities of war and coercive relationships (Amony 2015). This growing body of literature reveals that women's experiences and roles during war cannot be reduced to the passive and ever-vulnerable status of "bush wives" and/or "sex slaves." Instead, women and girls frequently stage acts of resistance or at times take on active combat roles (MacKenzie 2012), thereby operating as "active agents" (Utas 2005) in multiple ways and domains.

For example, countering reductionist and essentialist portrayals of women as passive victims of conflict, Utas (2005) shows that women's actions and their agency are a matter of constantly adjusting tactics in response to the opportunities and constraints that characterize situations of armed conflict. Utas argues that 
women's agency "represents a range of realizable possibilities," qualifying women as "tactical actors engaged in the difficult task of social navigation" (2005: 426). Chris Coulter's (2009) anthropological study of "bush wives" in the Revolutionary Armed Forces (RUF) in Sierra Leone similarly moves beyond the essentialist portrayal of women as exclusively vulnerable, by paying attention to the active roles played by many women during the armed conflict. In Sierra Leone-as in northern Uganda and indeed elsewhere globally-female combatants, and especially those who were forcibly abducted, are almost exclusively portrayed as weak, vulnerable, and passive, often referred to as "bush wives" or "sex slaves." Challenging such essentialist representations, Coulter instead evidences the diversity of women's experiences and their agency during the war and in the postconflict period. Megan MacKenzie's (2012) work on female soldiers in Sierra Leone likewise pays attention to the active participation of women during the war and its aftermath, thereby debunking the prevalent myth that women do not (and cannot) fight and countering the general picture of women and girls exclusively as victims of conflict. MacKenzie's examination empirically contributes toward a better understanding of female soldiers' experiences of and involvement in and after conflict, including their agency, which is important for crafting effective postconflict policies.

In postconflict Peru, Kimberly Theidon (2012) similarly illustrates the numerous ways in which women give meaning to their harms, which she refers to "womanly narratives of heroism" (2007: 474). In her work on East Timor, Kent (2014) also describes that the lived experiences of women in forced relationships are much more complex than commonly portrayed by liberal human rights approaches. While narrowly presented as caught in relationships of coercion and violence, the women, Kent notes, often staged acts of resistance to reassert their independence within these relationships. And in one of the few existing cross-national and multicase studies on this topic, Denov (2007) traces the experiences of women and girls as participants and resisters of violence and as agents during the conflicts in Angola, Sierra Leone, Mozambique, and northern Uganda. Arguing that "girls in fighting forces are not simply silent victims, but active agents," Denov shows that women and girls made remarkable "efforts to bring about change for themselves and by themselves" (2007: ii). Denov likewise shows that the obstruction of women's and girls' agency in conflict zones leads to their frequent discrimination in the context of postconflict measures, having problematic implications and consequences for their postwar recovery (also see MacKenzie 2012).

Specifically focused on northern Uganda, the autobiographic accounts of Evelyn Amony (2015), who was forcibly married to LRA leader Joseph Kony, and of Grace Acan (2015), both of whom spent more than ten years with the rebel group, contribute to a more nuanced and detailed understanding of women's agency in conflict and postconflict settings. These personal narratives challenge stereotypical ideas of war-affected women, unearthing instead the complex ways 
in which female survivors navigated life inside and outside the LRA and politically engage as human rights activists. In the introduction to Amony's account, Erin Baines acknowledges that "previous studies highlight the diverse roles women and children play in rebel armies..., yet we know little about how persons within such groups perceive, experience, and bear witness to war over time. We know even less from the perspective of women' themselves" (2015: xvii). Together, Amony's and Acan's narrations of their experiences refute numerous stereotypes, "thereby repainting the picture of women in the LRA as not just vulnerable and passive victims but also empowered agents and actors" (Schulz 2016: 312).

Drawing on extensive and long-term research with women and girls formerly abducted by the LRA, Erin Baines (2017) further explores female political agency in northern Uganda. She argues that abducted women were not just passive victims, but instead navigated complex social and political worlds, both during captivity in the LRA as well as upon return to civilian life postconflict. Baines's work illustrates how women and girls who returned from LRA captivity in the postconflict period sought to rebuild "a web of relations that constitutes meaningful life" (2015: 328), and how these acts of rebuilding relationships constitute aspects of victims' political agency.

In combination, these different studies challenge essentialist portrayals of gendered victimhood in situations of armed conflict, evidencing that women and girls instead frequently exercise political acts of agency to come to terms with their harmful experiences. Despite this much-needed attention to the agency of female victims, however, the manifold ways in which male survivors of sexual violencewho are similarly portrayed as helpless and ever-vulnerable-also engage with their harmful experiences and exercise agency have not yet been sufficiently examined (see Touquet and Schulz 2020). Taking inspiration from this growing body of critical feminist IR scholarship, this chapter offers a necessary examination of the different strategies Acholi male survivors employ to come to terms with their gendered harms.

\section{THEORIZING POLITICAL AGENCY}

Before introducing the survivors' associations as a particular space for exercising agency and proceeding with the analysis, I offer a few notes on theory in order to provide a brief but hopefully coherent conceptualization of political agency that will underpin the analysis to follow. ${ }^{1}$

In its broadest sense, agency refers to the human capacity to act, "a capacity that is not exercised in a vacuum but rather in a social world in which structure shapes the opportunities and resources" to act (Björkdahl and Selimovic 2015: 170). In this reading, agency is centrally composed of autonomy and intention and is dependent on structural factors. Here, however, the focus rests specifically on political agency in a widened sense, "located in the social world that the 
embodied individual encounters in multiple different subject positions, averting, accepting and altering them through individual and concerted action" (Häkli and Kallio 2013: 191). As further emphasized by Björkdahl and Selimovic (2015: 171), political "agency should not only be understood as overt political (re)action, but may also be enacted through 'life projects' that may not necessarily be formulated as [formal] acts of resistance but that still have transformative effects in the gendered everyday."

Throughout most political science and IR scholarship, the "political" is commonly conceptualized in a formal and public sense, focused on states or institutions and necessitating a degree of autonomy enjoyed by rights-bearing individuals and guaranteed through liberal nation-states. But such a confined conception of the "political" excludes a range of politicized activities, actions, and choices, and assumes "that subordinate groups essentially lack a political life" (Scott 1990: 199). By departing from narrowly formalized understandings of "politics," I instead focus on forms of the "political" and agency that do not only emerge on the macrolevel and in (semi)institutional settings, but instead more widely in myriad "interactions and relations among and between persons" (Baines 2017: 14).

This broadened conception of political agency is underpinned by a relational understanding of politics as an integral part of people's everyday lives that requires attention to the phenomenologies of politicized action. The political is therefore conceptualized in an Arendtian tradition as "a form of activity concerned with addressing problems of living together in a shared world of plurality and difference" where "the space of this sharing is constituted by active agents" (Barnett 2012: 679). According to this relational understanding, a whole variety of actions and gestures can enter the realm of the political when individuals recognize and assert "themselves as particular subjects, in relation to others, to the structures in which they are situated, and to subject positions that may be imposed on them" (Elwood and Mitchell 2012: 4). Arguably, this relational approach to political agency is particularly applicable to the collectivist society of the Acholi in northern Uganda, where personhood and sociality rest upon social collectivism and communal structuring in a relational sense, framed within the categories of dano adana and/or bedo dano (p'Bitek 1986), as covered in the previous chapter.

Political agency as employed here thus broadly involves a wide range of choices, actions (or nonactions), and strategies within the public and private spheres, employed by individuals and communities aimed at remaking a world and reconfiguring their lives and relationships, as well as at reasserting their personhood, identity, and self, including in the aftermath of violence and injustices. Such a conception of political agency broadens much of the IR and conflict-studies literature's (neoliberal) treatment of agency as equated with resistance or survival strategies (see Mahmood 2001) and recognizes more broadly the manifold and relational ways in which survivors exercise political choices to come to terms with their war-related experiences. 
This wider and open-ended theoretical understanding, however, implies the danger of potentially overpoliticizing everything and inevitably raises the analytical question of when and where to detect political agency. Ultimately, "agency [is] not a general characteristic which actors either have or lack, but a quality that actors' doing may have in a specific context" (Menzel 2018: 4), indicating the existence of spatially and temporally contingent structural factors and conditions for agency. For Menzel, a measurable conception of agency thus necessitates a differentiation between motivational (or intentional) and effective dimensions, which specify "that actors consciously want to do something (motivational dimensions), and are able to achieve at least somewhat desired effects (effective dimension)" (ibid.: 10). These contingencies and the contextual openness of political agency also imply that it is inherently difficult-if not impossible-to predetermine which activities or actions are or become political (and which are not) under any given circumstances. The particularities and specific understandings of the political may therefore often be unknown in advance and "thus need to be worked out empirically" (Häkli and Kallio 2013: 195).

To ultimately recognize specific instances as relational and political, Baines argues that "stories provide insight into a set of historical truths that otherwise slip from view in empirical and general theories . . . , enabling a more complex analysis of the living subject and opening space for consideration of the workings of power in the counters of life" (2015:321). Stories in particular can offer meaningful interpretations of the complexities of harms and agency in wartime and can serve to illuminate "how people perceive of themselves and in relation to others" (Patterson and Renwick Monroe 1998: 317). After all, through the stories they narrate, "people locate themselves as agents in the various social worlds they identify with ... or inhabit" (Fujii 2018: 3). To this end, I will draw on survivors' testimonies and stories to tease out the ways in which support groups offer avenues for male survivors to exercise different forms of agency.

\section{An Example of Political Agency: Navigating Silence and Disclosure}

Before proceeding with the case-specific analysis, I want to illustrate what is meant by political agency by referring to an example of a male survivor from northern Uganda who navigated what can be referred to as "engaged silences" as a form of political agency.

Throughout the literature on the nexus between gender, conflict, and silence, it is often argued that when externally imposed, silencing can further entrench gendered harms. Here, however, I want to focus on how (and under which conditions) silence can be agentive and can become a powerful political tool for survivors to deploy strategically. To examine the role of silence as a form of agency, it is important to recognize a distinction between being silenced (externally, involuntarily) and voluntarily choosing to be silent. I thus specifically employ Keating's (2013) framework of "engaged silences" - which broadly includes three forms: silent 
refusal, silent witness, and deliberative silence-in order to tease out the multiple forms and functions of silence. For Keating, silence can be a (collective and individual) form of resistance to power and must thus be understood as potentially agentive when deployed by politically marginalized groups (see Thomson 2019). For "silences are modes of being and self-representation which give individual social actors the active agency to reflect on, make sense of and represent their past experiences while simultaneously linking current predicament to the past and vice versa" (Dery 2018: 15).

To illustrate how silence can be(come) agentive, I refer to the case study of Okidi, a male survivor from the northeastern part of Acholiland. This example reflects the lived realities of numerous other male survivors whom I engaged with and who employ similar tactics and strategies of navigating silence and disclosure, thus constituting one particularly poignant illustration of my argument.

Okidi was arrested and taken captive by government soldiers of the NRA in mid-1986, just as the war in the north began. Like many other male survivors, Okidi was accused of being a former soldier fighting the newly instated Museveni regime. Because of his long, thick beard, he resembled one of the leading military opposition figures at that time who was previously a commander under Obote's regime. Okidi, who was a teacher at that time, was taken from the school compound where he worked to an NRA army barrack, where he was severely beaten, stabbed in the testicles with a bayonet, and anally raped by two soldiers. After two days of interrogation and torture, and while being transported to another army base on the back of a van, Okidi managed to escape and return home. However, he did not tell anyone about what happened to him. Due to shame and social stigma - coupled with the unavailability of medical services in rural northern Uganda during this time of the war-he did not seek any professional medical treatment. Instead, he nursed his wounds with warm water and traditional herbs by himself and chose to remain silent about his experience. More than two decades later, in 2013, he finally reported what had happened to him to the Justice and Reconciliation Project (JRP) - which conducted a study about incidents in this part of Acholiland during the war-and later to the Refugee Law Project, which offered medical treatment through rehabilitative support measures.

Following his much-needed medical recovery, he also decided to break the silence and report his experience to a broader audience. In 2014, at a specifically organized press conference in Gulu town supported by JRP and RLP, Okidi offered a thirty-minute account of his experience during the war, including the incidence of sexual abuse in 1986. This account was later published in the Acholi Times, an online English-language newspaper that focuses on sociopolitical developments in the Acholi subregion and that regularly features stories about the war and contemporary postconflict challenges. The article, published in September 2014 and thus twenty-seven years after the assault, describes what happened to Okidi in 
NRA custody and includes his full name, his location, and even a picture of him. In his home village and even within his family, however, nobody knows about his experience. He explains that "from 1986 to 2013, I never told anymore what happened to me, and then I only disclosed it to JRP and to RLP in 2013 and later to the newspaper in 2014. But here I don't talk about it, I still keep it confidential because from the people here I feel stigmatization. When people here are drunk, they will stigmatize me and undermine me and that will undermine my dignity as a human being."

During a conversation we had in early 2016, Okidi explained to me that because the press conference was held in Gulu town-located about 150 kilometers from his home village-and the newspaper is published online and in English, he does not fear that community or family members in his village will ever get to know about it. In fact, the newspaper is primarily read by an urban-based, young, and largely educated elite, or by Acholi diaspora communities in Kampala, Entebbe, and other bigger cities in Uganda as well as abroad. It remains largely unknown, or at least unread, in rural parts.

This example poignantly illustrates the spatial-geographic dimensions of silence, as well as the ways in which survivors can exercise agency by choosing which stories to narrate in which spheres, and where to maintain what could be referred to as a "protective silence." In this case, Okidi broke the silence in the public sphere to attain a sense of social recognition of his otherwise silenced and marginalized experience. At the same time, however, he deliberately and in an agentive capacity maintains his silence within his private sphere and his immediate surroundings in fear of negative repercussions, such as stigma, shame, and humiliation. By both sharing his testimony and maintaining a protective silence, Okidi acts politically and relationally, towards his family and community in maintaining that protective silence, as well as towards JRP, RLP, the Acholi Times and its readership by way of sharing his testimony. He thus navigates his experience and vulnerability in different settings, thereby refuting the stereotypical representation of the ever-vulnerable survivor without a voice.

\section{THE MEN OF COURAGE SURVIVORS' GROUP}

In addition to navigating silence and disclosure in complex ways, as illustrated through this example, male survivors in northern Uganda also exercise differing forms of political agency in the context of survivors' groups. Departing from these conceptual reflections, here I focus on the roles of survivors' support groups and the spaces they facilitate for survivors to be(come) agentive by way of engaging with their experiences in multiple ways. To this end, I specifically draw on the Men of Courage survivors' group, composed of three subgroups located across Acholiland, which I will first introduce below. 


\section{Survivors' Groups and Dealing with the Past}

Throughout the postconflict literature in general, survivors' groups and organizations are featured in different capacities. For instance, previous studies have analyzed how survivors in groups engage with wider processes of dealing with the past and postconflict reconstruction. To illustrate, Humphrey and Valverde (2008) show that victims' groups in Argentina aid survivors in demanding recognition from the state, while Rombouts (2004) unveils the manifold roles of survivors' forums in advocating for reparations in postgenocide Rwanda. Together these (and other) studies demonstrate that uniting individual survivors under the umbrella of an association can facilitate an environment that enables survivors to collectively engage with external and macrolevel processes in postconflict spaces.

Fewer studies have examined how groups can offer active coping strategies that may contribute to collective healing and recovery. In Nepal and East Timor, for instance, groups aid families in reconstructing their identities after having been impacted by conflict-related political disappearances (Robins 2009). Likewise, members of the Khulumani support group in South Africa, in a submission to the country's Truth and Reconciliation Commission (TRC), recommended the creation and maintenance of survivors' support groups as means to "address the ongoing problems resulting from the TRC and conflicts of the past [because] groups will serve as a living memory ... while on the other hand mobilizing more resources for the empowerment of victims" (CSVR and Khulumani 1998).

Despite these positive aspects of survivors' groups, however, some challenges persist. Many victim-survivor associations are shaped by hierarchies among survivors, and there are often stark power discrepancies between different members exercising diverging levels of influence. Likewise there are frequently divisions between separate groups as well as between survivors who are members of groups and those who are not part of an association, further entrenching tensions within and between conflict-affected communities, such as in Northern Ireland. Similarly, in northern Uganda, various survivor-led groups stopped operating due to internal disagreements over what the group ought to concentrate on. The fact that groups are often established or supported by external actors can constitute an additional challenge, implying victim dependencies upon outside bodies. As argued by Kent in the context of East Timor, "the agency, autonomy and 'home grown' nature of victims' groups should not be overstated. . . Victims' groups have been intensively cultivated by national and international NGOs. Without this support, it is likely that many of their activities would not be sustainable" (Kent 2011: 447-448).

Overall, however, across these diverse scholarly engagements, survivors' groups are primarily analyzed as precursors to wider macrolevel and state-led processes. Yet, the potential for survivors to actively exercise agency and facilitate healing or justice through their participation in groups has not yet been sufficiently 
explored, especially within postconflict settings and through a gendered masculinities lens. The analysis pursued here thus aids our understanding of how conflict-affected communities can actively engage with their experiences on their own terms and in agentive capacities in the context of survivors' support groups, particularly so in the absence of more formalized support measures, as is the case for male sexual violence survivors in northern Uganda.

\section{Survivors' Groups in Northern Uganda}

Reflective of these global dynamics, in northern Uganda a variety of victims' groups exist in different forms and with divergent mandates, objectives, and foci, and variations in size, activities, and levels of organization. Most of these groups unite survivors of the conflict between the LRA and the government of Uganda and assist victims in advocating for their demands and pursuing their quests for justice. Other groups also provide more practical assistance, including peer support, income-generating activities, and shared finance schemes, such as Village Savings and Loan Associations (VSLA). Locally referred to as bol cup, various forms of savings and farmers group existed prior to the conflict in northern Uganda (Allen 1987), and therefore, the current postconflict groups qualify as a "continuation of local methods of self-help and income generation," although their function "now extends to providing some form of non-material comfort too" (McDonald 2014: 256). While smaller groups on the community level primarily engage in these forms of immediate practical support for survivors, quests for justice and reparations have mostly been taken up by larger claimants' associations, such as the Acholi War Debt Claimants Associations, thereby further entrenching hierarchies between different types of groups.

On a more conceptual level, by uniting larger numbers of survivors under the umbrella of an association, groups in northern Uganda also enable their members to more widely disseminate their demands and needs. As articulated by a member of a victims' group, "When we organize ourselves we can raise our voices and make them be heard by the government in order to receive help" (Akullo Otwili and Schulz 2012: 2). The postconflict context in northern Uganda continues to be characterized by restrained access to services for conflict-affected communities. Many survivors often do not benefit from any of the developmental programs implemented by either the Ugandan government (such as the Peace and Recovery Development Plan) or by the countless nongovernmental agencies, mainly due to a lack of practical measures or their inaccessibility for rural communities in particular. This creates a vacuum of provisions and assistance for the majority of victims of the conflict. In a variety of ways, such groups therefore constitute key avenues "in which communities [are] coping with the legacy of the conflict" (McDonald 2014: 255). Despite these different positive aspects of survivors' groups, however, many of the challenges pertaining groups in general as listed above also apply in northern Uganda, including hierarchies between survivors within and outside the 
groups, power discrepancies among members, and dependency on outside actors, particularly on NGOs.

Varying in their composition, some groups bring together different categories of victims within one association, while others primarily unite specific (sub)categories of survivors. Focusing on gender, some groups, such as the Women's Advocacy Network (WAN), provide a platform for conflict-affected women who have returned from LRA captivity with children born as a result of rape, in addition to other groups of female as well as male survivors of sexual.

\section{Male Sexual Violence Survivors' Groups: Men of Hope, Peace, and Courage}

Here I specifically want to focus on the groups of male sexual violence survivors in Uganda that receive support through the Refugee Law Project, alongside other support groups that RLP works with. In addition to one umbrella association in the north, RLP assists and collaborates with two other male survivors' groups in Uganda: the Men of Hope Refugee Association Uganda (MOHRAU) in Kampala, established in 2011 and composed of over 100 members who are refugees from East Africa's wider Great Lakes Region; and the refugee support group Men of Peace (MOP), established in 2013 and located in Nakivale in southwestern Uganda, one of the country's largest refugee settlements, uniting more than 230 members from neighboring countries across the region.

In these two groups, survivors' harmful experiences of sexual abuse intersect with their marginalized status as refugees living in Uganda, implying additional vulnerabilities and challenges, such as no (or restricted) legal status, limited access to income-generating activities, and insufficient social support networks. Both associations, although to varying degrees, advocate for the rights of male refugee survivors of sexual violence on the international, national, and communal level. The groups' activities “include community awareness raising, sensitization, advocacy, and documentation of sexual violence against refugee men and boys" (Edström, Dolan, et al. 2016: 1). While these two associations have produced audiovisual materials or annual reports, no such materials so far exist about the group from northern Uganda.

During the first meeting of the South-South Institute (SSI) in Kampala in July 2013, individual male survivors from Acholiland had the opportunity to engage with other male survivors from within and beyond Uganda. ${ }^{2}$ Unlike their counterparts from other areas of the country, however, they were not yet systematically organized as an institutionalized group. Inspired by the recently established Men of Hope and Peace associations from Kampala and the Nakivale settlement, individuals from northern Uganda expressed their motivation to establish a group for male survivors in the Acholi subregion themselves. During the institute, the male survivors from northern Uganda were repeatedly referred to as men of extraordinary courage for openly coming forward and sharing their stories about 
government-perpetrated sexual abuse in this highly politicized context and despite their age. In relation to this, one service provider, who was present at the institute, explained that "when elders speak out about [sexual violence], it takes particular courage," thus coining the group's name, Men of Courage.

Composed of three subgroups scattered across the Acholi subregion, the Men of Courage umbrella group is less organized and centralized compared with its partnering associations in Kampala and Nakivale. Northern Uganda's vast geographical area and the widespread occurrence of sexual violence against men across large parts of the north (see chapter 3 ) imply organizational challenges of uniting survivors from different locations under the umbrella of one association. During one of the workshops, representatives from the different subgroups expressed their interest in further uniting the group and setting in place a more formal and centralized structure in order to provide members with better access to and benefits from developmental programs provided by the government and nonstate actors alike, a goal toward which the umbrella group is currently working. The chairperson of one of the subgroups clearly stated, "We want to transition our status as a group to become an association to be registered with the subcounty ... so we can be assisted."

Varying in size, membership, structure, and activities, the three subgroups are called Alany Pa Mony Lii ("humiliation by combatants is painful"), Kany Akanya ("just persevere"), and Ciro Areem Tek ("it is hard to bear pain"). Established between 2013 and 2015, these are quite new groups, each with between ten and forty-plus members. In addition to these groups, another group, called Tim Kikomi Wek I Cang ("Do it yourself so that you can heal"), previously existed but now more or less dissolved following the death of their chairperson, demonstrating the dependency of such groups on strong (individual) leadership, which arguably constitutes a challenge in itself. The names of these groups in themselves indicate not only the harms suffered by male sexual violence survivors (e.g. humiliation, pain) and some of the obstacles they face as individuals and as groups (e.g. dependency), but also the ways in which they as survivors, individually and collectively, want to move forward (e.g. perseverance).

Overall the groups carry out a variety of activities, including most commonly peer support, and members have received basic training by RLP to provide psychological support for counseling one another. Additional activities include organized income-generating activities. One of the groups, for instance, cultivates beehives to generate a small profit by selling honey. The same group also organizes a saving scheme (under the umbrella of a VSLA) for members and collectively conducts agricultural work. Members of the groups have also received psychological and physical rehabilitation at Saint Mary's Hospital Lacor outside of Gulu town under the Beyond Juba Project previously run by RLP. ${ }^{3}$ According to survivors, such activities have helped them to respond to their everyday postconflict challenges, including poverty and dependency. The Men of Courage chairperson 
explained that "the members of the group have decided that they should not be spoon-fed by others but that they can stay on their own and fend for themselves without living in poverty like before."

According to survivors, the groups also enable members to collectively deal with and respond to stigmatization. "We are now in a group and it is harder to stigmatize us," one male survivor explained, while another member attested that "prior to joining the group, there was a lot of community stigmatization, but now we know how to deal with it." While the stigma surrounding male-directed sexual violence persists (chapter 4), for those whose experiences of sexual abuse are known among the community and who are consequently stigmatized, the groups constitute a support network to cope and engage with these negative and often harmful community reactions. Similarly, various survivors believe that the groups' advocacy initiatives, as further explained below, and the comfort of being in a larger group with other survivors can potentially reduce the levels of stigma, including its psychosocial consequences.

Despite such benefits, however, the groups also face multiple challenges. For instance, and although the groups partially helped some survivors to deal with numerous social consequences and harms, stigmatization often prevails. One survivor explained that "even now that we are organized, the people in the community still name-call us and stigmatize us. We still have to meet in silence." Due to this, meetings are sometimes held in secret, and some of the groups exist more or less undercover. One of the groups, for instance, is officially registered as a VSLA and does not publicly identify as an association of male sexual violence survivors, and none of the groups' names includes specific references to sexual violence against men. Numerous survivors believe that a larger group of male survivors would draw attention and suspicion, thus having the reverse effect of what has been explored above and evidencing the ambivalent role and positioning of these groups and of male sexual violence survivors in Acholiland. Linked to these fears of stigmatization are security threats from community members and state agents, which some of the survivors were previously exposed to. Survivors who have broken their silence continually discussed such threats in workshops, saying they are often accused of sabotaging the government by publicly talking about government human rights violations, including sexual violence.

As with other survivors' associations in different contexts, certain differences among members within as well as across the separate groups exist. For instance, some members are more engaged and active as well as more influential than others, and they speak out more frequently. For instance, the umbrella association's chairperson, Julius Okwera, embraces a higher-profile role and regularly represents the groups in public meetings, while other members primarily engage internally or participate to a lesser extent in advocacy work. Another challenge is the groups' heavy dependence on outside actors, and especially on RLP. As articulated by one survivor within the group, "We were unsure about how to help ourselves 
until RLP assisted us." At the same time, survivors emphasize their motivation to mitigate this dependency and transition toward a more independent association. In many ways, this ambivalent situation illustrates the complexity of victim dependencies when survivors' groups are closely linked to or even established by civil society actors.

\section{“HERE I CAN TALK FREELY ABOUT WHAT HAPPENED TO ME"-EXERCISING AGENCY IN SURVIVORS' GROUPS}

But how do groups relate to agency? ${ }^{4}$ Here I argue that the Men of Courage association enables male survivors to engage with their experiences and address their gendered harms, thereby creating pathways for them to exercise myriad forms of agency in four fundamental ways: (1) by helping survivors to renegotiate their gendered identities; (2) by (re)establishing relationships, thereby mitigating isolation, ostracism, and exclusion; (3) by providing safe spaces for survivors to share their narratives and experiences through storytelling; and (4) by aiding survivors in the struggle for recognition of their harmful but otherwise silenced experiences. From the perspectives of male survivors, these four functions respond to and begin to address (some of) survivors' sexual and gendered harms. In this reading, survivors' groups constitute a conduit through which survivors can exercise agency and ultimately through which a sense of justice on the microlevel can be conveyed, among survivors themselves and outside the purview of formal and state-driven institutions, as several survivor attested and as I will demonstrate toward the end of this chapter. In this vein the groups use the proverbial "short stick," of being close to a "problem" in order to contribute to a solution, as explained in the introduction.

\section{Renegotiating Gendered Identities}

First, groups aid male survivors in a process of renegotiating their gender identities as impacted because of the sexual violations (chapter 4). This constitutes an integral aspect of exercising agency and acting politically in relation to their communities as well as their own sense of identity in synch with the conceptual understanding of political agency laid out above. Survivors' groups thus begin responding to survivors' compromised masculinities as one of the most prevalent harms resulting from male-directed sexual violence.

The peer support that the groups engage in is loosely based on a theoreticalconceptual model of positive psychology that "takes into account the role of social interactions and support in how people process traumatic events" (Edström, Dolan, et al. 2016: 17). Through this collective peer-to-peer support, survivors develop "a critical awareness about their situation," which in turn can facilitate a mutual, collective process of "unpack[ing] the causes and impacts of these experiences" (ibid.: 28). Engaging with these effects "has a deep and liberating influence 
on [their] individual sense of personhood and self-worth" (ibid.) and is important in order for survivors to renegotiate their gendered identities, although clearly additional components and processes may be necessary to ultimately facilitate such processes.

Addressing the UK House of Lords' Committee on Sexual Violence in 2015, RLP director Chris Dolan, who works closely with these survivors' associations, explained that "those groups allow [survivors] to reestablish a sense of social identity and a sense of being respected again. . . . Being in a group helps to give back a sense of being recognized as an adult and as a man" (Select Committee 2016). As articulated by one survivor, "Before we came together, we had a lot of feelings of being less of a man, but since being in a group, the feelings . . have reduced."

The groups' peer support and collective economic activities have, according to one survivor, "economically empowered us and psychologically rehabilitated us." For instance, because of the groups' income-generating activities, male survivors are reenabled to help provide for their families. The groups thus contribute to a longer and multifaceted process of reinstalling male survivors in their role as providers, one of the central components of the Acholi model of hegemonic masculinity. This immediately addresses their gendered harms and initiates a process of reversing the displacement from gendered personhood in a relational way.

Nevertheless, criticism can be raised, especially from a feminist standpoint, that the activities of the groups thereby risk (re)installing and enforcing patriarchal gender orders. Helping male survivors to regain traditional masculine roles, responsibilities, and positions could further entrench hetero-patriarchy and thereby further fuel gender inequalities. This would obviously stands in contrast to feminist projects of gender justice, which seek to dismantle these very patriarchal orders and relations. Critical feminist IR scholarship increasingly recognizes that redress, justice, and repair mechanisms for men impacted by conflict may often depend on a return to and restoration of masculine privilege that rests on hetero-patriarchal and oppressive gender orders. For instance, Megan MacKenzie (2012) has argued that throughout the postconflict literature, a "return to normal" in the aftermath of war often implies a return to particular forms of patriarchal gender orders. Drawing on empirical research in Israel/Palestine, MacKenzie and Foster theorize these dynamics as "masculinity nostalgia," "associated with a romanticized 'return to normal' that included men as heads of household, economic breadwinners, primary decision-makers and sovereigns of the family" (2017: 15). Assistance or redress for conflict-affected men that specifically seeks to repair old gender ideals can thus rely on oppressive and heteronormative gender norms, identities, and hierarchies, therefore potentially involving compromises with unintended consequences for gender equality.

As explored in the previous chapter, however, men across Acholiland are evaluated against the dominant model of hegemonic masculinity by themselves as well as their wives, families, and communities, and they are considered to be less of a 
man if they are unable to live up to and fulfill these social requirements. For male survivors to transition and "remake a world" (Das, Kleinman, et al. 20o1), renegotiating their gendered identities is therefore critically important. As emphasized by survivors themselves, reenabling them to contribute to their families and communities is a crucial part of this process of reconnecting with manhood.

At the same time, research with the Men of Hope support group in Kampala finds that "the collective consciousness-raising within the group has also begun to challenge many members' stereotypical ideas around masculinity and manhood, as well as gender equality and views on women" (Edström, Dolan, et al.: 40). The engagement in the group and the sensitization and awareness-raising through the collective sharing of experiences often facilitate opportunities to forge new, alternative types of masculinities for male survivors. In the case of Men of Hope, for instance, "several members appear to reject many traditional inequitable norms and ideas" related to masculinities (ibid.).

This aligns with my own observations from northern Uganda, where male survivors at times demonstrated a rejection of traditional and often restrictive ideals of masculinities. For example, one survivor explained that "being a man in our culture means ... that you cannot be weak. This meant that we could not admit to what happened to us and could not seek any support, which really made it worse for us." Through the groups, male survivors thus begin to renegotiate their own gendered identities shaped by new (and possibly more gender egalitarian) understandings of masculinity.

Overall, support groups thus aid male survivors in facilitating a process of renegotiating their gendered identities and thereby begin to respond to the violations' immediate gendered effects-enabling survivors to exercise agency in relational and politically relevant ways.

\section{Reestablishing Relationships}

The groups furthermore aid male survivors in (re)establishing relationships, primarily among themselves within an intragroup setting. Indirectly, and although to a lesser extent, groups also aid male survivors in renegotiating relations with their families, communities, and social networks, which were previously impaired because of the sexual violations and the resulting stigmatization. According to survivors, (re)establishing these relationships can mitigate the isolation that prior to joining the groups characterized their lived realities, thus constituting an important component of "a right way forward in the aftermath of wrongdoing" (Porter 2017). Especially in a highly relational and communal society such as the Acholis (p'Bitek 1986), relationships are integral and necessary for the preservation of highly valued social harmony, and thus constitute an important element of male survivors' agency.

As previously discussed, compromised relationships constitute a fundamental harm resulting from the sexual violations, and many survivors live in isolation, 
ostracism, and social exclusion. Finnström (2003) writes that in Acholi culture, "to be forced to live in solitude, a total restriction of the ordinary life, disconnected from family and relatives is very distressing" (70). During the workshops male survivors themselves emphasized that joining the groups helped to connect with other survivors and to establish relationships, and that some of the activities further helped them to (re)integrate in their wider communities.

According to survivors, these group processes also mitigate isolation and help them to escape loneliness, which prior to joining the groups was often characteristic of survivors' lived realities (Schulz 2018a). Based on research with members of survivors' associations in postconflict Peru, de Waardt (2016) argues that "a motivation for participating in the activities of the [victim-survivors' associations] has to do with being in the company of others who have experienced the same type of hardship" (445). This reflects the viewpoints of many male survivors in Acholiland, one of whom explained that "bringing us together like this helps us to understand that we are not alone but that others are also affected and that it also happened in many other places." Another participant similarly attested that "coming together in a group made us more courageous," and that "it helped us to come out and be comfortable among other people." A key informant who directly works with male survivors further explained that "male victims are not feeling safe in any spaces, except for sometimes in their homes, but especially in cases in which the violation happened in their home or compound, they even do not feel safe in their home. ... As a result, they do not feel safe anywhere, with the only exception being the group."

By providing safe spaces and communities, the groups help mitigate isolation and "challeng[e] the reasons for marginalization and ostracism experienced by male survivors" (Edström, Dolan, et al. 2016: 6). Within the support groups, therefore, "feelings of isolation and hopelessness are countered by the building of relationships with other men that understand a shared reality" (28).

Discussing how conflict-affected communities in Sierra Leone "were able to find peace and justice by regaining a sense of normality ... through everyday practices," Laura Martin (2016: 401) similarly shows how survivors' groups provided a space for rebuilding relationships and reestablishing social connections. Through "creating spaces where war-related experiences can be remoulded and relationships repaired" (400), the groups hence contribute to what Veena Das (2007) terms the "descent into the ordinary" in the wake of un-ordinary war-related lived realities, helping to remake and recover life. Communities that are transitioning out of armed conflicts often long for these everyday experiences and a sense of normality, and that desire for the ordinary often becomes a focus and locus of their agentive strategies and choices. Reflective of the sentiments expressed by male survivors in northern Uganda, Martin (2016) observed that "these seemingly mundane interactions aided people in moving away from feelings of isolation ... towards feeling a greater sense of community" (409-410). These dynamics 
illustrate that the everyday can be a crucial "space of negotiation and renegotiation of social relationships that make life meaningful" (Baines and RosenoffGauvin 2014: 282), and thus of social repair, which in turn becomes the focus of survivors' agency.

Although the groups do address male survivors' harmful experience of social invisibility, misrecognition, and humiliation, the previous experience of being and feeling abandoned cannot be entirely negated. Political philosopher Stauffer (2015) argues that "not being heard or being ignored impacts how the past resonates in the present" (3). But Stauffer (2015) also suggests that to counter marginalization and isolation, "a survivor will need broad social support that functions as a promise that, though she [or he] was once abandoned by humanity, that will not be allowed to happen again" (7). Hence, victims' support groups can be instrumental for countering abandonment in an agentive, relational, and politically relevant manner. As Stauffer argues, the "conditions of the surrounding world will make all the difference to a person trying to create a livable present moment in the wake of past harm" (ibid.: 129). She specifically notes the strength that survivors can gain from groups and supportive environments in order to break out of the isolation and loneliness. Edström, Dolan, et al. (2016) further echo such observations: “The nature of peer-to-peer support helps build a sense of belonging that assists survivors of violence to overcome the resulting stigma, isolation and erosion of trust and dignity" (28).

At the same time, different aspects of the groups, such as the communal incomegenerating activities, reenable male survivors to provide for their families, which sometimes also catalyzes a longer process of reestablishing relationships with their families and wider communities. As theorized above, acting relationally toward their families, communities, and themselves makes these instances politically relevant and therefore qualifies them as episodes of male survivors' political agency.

\section{Agency, Voice, and Storytelling}

In addition to facilitating these processes of renegotiating gender identities and repairing relationships, the groups also create safe spaces for survivors to share their stories, voice their concerns, and thereby exercise agency. Addressing the Select Committee on Sexual Violence of the Britain's House of Lords, RLP director Chris Dolan attested that "with the groups we are able to create platforms for them to speak for themselves" (Select Committee 2016). Drawing on this, I additionally argue that the groups enable survivors to exercise agency by way of articulating their demands and engaging in a process of storytelling as a culturally appropriate component of dealing with the legacies of the past. In this capacity the groups further address survivors' gendered harms of exclusion and isolation and respond to the externally imposed silencing of survivors' experiences.

With regard to agency, one central concern for postconflict reconstruction and transitional justice processes is that the professionalization of the field has led 
to the emergence of postconflict and/or transitional entrepreneurs (Madlingozi 2010) who are speaking on behalf of victims. Potential risks associated with this include "resilencing victims, negating their potential for agency and reproducing the sense of powerless" (McEvoy and McConnachie 2013: 498). By encouraging survivors to share their stories and articulate their concerns, the groups stand in contrast to these problems of speaking for others, by offering survivors a platform to speak for themselves.

For one survivor, the group offers "a venue where I can talk freely about what happened to me and others listen to me and acknowledge my story." During group meetings, male survivors regularly sit together and talk about their experiences in an environment where they feel safe and protected. "When we meet and sit together, we can talk freely about what happened to us, because everyone understands and had the same experience," another male survivor said. The groups thereby facilitate safe spaces for acts of storytelling, which, according to anthropologist Michael Jackson, provides possibilities for subjective experiences to become social. As Jackson writes (2002: 245): "Stories make it possible for us to overcome our separateness, to find common ground and common cause. To relate a story is to retrace one's steps, going over the ground of one's life again, reworking reality to render it more bearable. A story enables us to fuse the world within and the world without. In this way we gain some purchase over events that confounded us, humbled us and left us helpless. In telling a story we renew our faith that the world is within our grasp."

In Acholiland, storytelling constitutes a philosophical act, and cosmology and morality are expressed most prominently through the oral tradition. Recall, for instance, the proverb presented and contextualized in the introduction to this book as an expression of this strongly pronounced oral and story culture. In their previous work on storytelling, gender, and justice in northern Uganda, Baines and Stewart (2011) further illuminate how the "Acholi communal practice of wang-o (telling stories around the fire pit) is an everyday practice of inviting discussions of social life" (248), thus constituting a culturally appropriate space to voice one's stories and experiences. In the context of male survivors' groups, meetings do not necessarily always take place within the context of wang-o. Nevertheless, for their gatherings survivors often choose the comforting shade of a mango tree or the seclusion of a grass-thatched hut as equally culturally resonating venues. Indeed, two of the group workshops were held in such localities in members' homesteads.

In this context, stories are not necessarily told for external purposes, such as breaking the silence, but more "for survivors to testify to other survivors" (Baines and Stewart 2011: 260). As theorized by anthropologist Fiona Ross (2003), stories in such contexts "are particular instances, synopses of experiences, told at particular times for particular audiences and located in specific contexts" (332). Linked to the process of renegotiating identities and reestablishing social relations, Baines and Stewart (2011) argue that "stories told among survivors, in informal 
settings ... provide a space in which survivors might renegotiate their social marginalization and insist on their innocence and self-worth" (247). In the wake of violence, therefore, "storytelling restores humanity through the reconstruction of one's life story" (ibid.). Storytelling thereby implies the potential to reconstitute families, communities, and social relations, all of which are crucial aspects in "remaking a world" (Das and Kleinmann 2001) and centralize as well as resemble the relational understanding of politics that is required to analyze these processes as instances of survivors' political agency.

In their study on storytelling in Acholiland, Baines and Stewart (2011) therefore claim that "storytelling . . . becomes a form of justice making that restores the imbalances of individual value" (258). Drawing on my own findings, I transfer their claims to the situation of male survivors in support groups in northern Uganda, which elevate survivors' voices, enable them to exercise agency, and share their stories in safe spaces that are not sanctioned by the overall silencing of sexual violence against men. Survivors getting together in groups thus qualifies as what Das and Kleinman refer to as the "creation of alternate (public) spheres for articulating and recounting experience silenced by officially sanctioned narratives" (2001: 3). The capacity of these groups to facilitate an alternative platform for storytelling and articulating voices must thus be situated in the context of a vacuum of official forums or public spaces to talk about sexual violence against men.

Nevertheless, and despite these dynamics, narrating and recounting harm can of course never be an easy task, either in official spaces, such as publicized truthtelling initiatives, or in alternative forums on the microlevel. As emphasized by Ross, stories "may render testifiers vulnerable" (2003: 332) and can indeed have unintended consequences, such as long-term negative emotional and psychological implications. The safe environment of the victims' groups is therefore crucial to lay the soil for supportive spaces where survivors can tell their stories on their own terms, at their own pace, and for a particular audience within a familiar and protected setting, to mitigate some aspects of the potential vulnerability arising from narrating harmful experiences. Retaining the stories within the safe confines of the groups also means that survivors can narrate their experiences without necessarily having to fear negative repercussions, including social stigmatization, shame, and further humiliation. Further, since the acts of storytelling are restricted to an intragroup setting, not told for outside consumption, some of the previously detected challenges of storytelling within the context of truth commissions, such as the potential co-opting, external reproduction, and politicization of individual testimonies, arise less prominently in relation to the groups. As articulated by one survivor, "The group is a place where we can share our testimonies in dignity," while another survivor proclaimed that in the group, "I can talk freely about what happened to me without having to fear any consequences or negative reactions."

Overall, and despite some potential drawbacks of intragroup silences and the nature of testifying, Acholi male survivors' experiences suggest that storytelling 
within the groups enables them to exercise agency and articulate their voices, to counter the silencing of male-directed sexual violence and survivors' experiences, thereby responding to prior harms and in part addressing their vulnerabilities. All of these are crucial aspects of survivors' relational and political agency in relation to themselves, the groups as institutions, and other members in the association.

\section{The Struggle for Recognition}

Situated in this context where male sexual harms are heavily silenced, survivors also want their harmful experiences to be recognized not only among themselves, but also by the wider society, outside actors, and the government. ${ }^{5}$ Here I concentrate on how groups aid male survivors in obtaining recognition of their harmful experiences, among themselves and societally, and how this constitutes a significant aspect of survivors' agency by way of responding to the systematic marginalization of survivors' experiences.

In northern Uganda, recognition of sexual violence against men seems particularly important, certainly for survivors themselves, because of the severely silenced character of these crimes. At the same time, however, recognition of male survivors' experiences and harms can take on an ambivalent character, as it carries with it the possibility for negative social consequences, such as additional social stigma and communal isolation. In light of this, through the groups male survivors primarily seek wider societal recognition of their experiences and of themselves as survivors rather than merely localized and individualized recognition on the community level. These dynamics thereby resonate with Okidi's experience of navigating silence, disclosure, and recognition as presented in the case study above. At least to some extent, the survivors' groups enable male survivors to operate within and to actively navigate these spatial nuances and influence their respective levels and audiences for recognition.

For male sexual violence survivors in Acholiland, the overall silencing of their painful experiences can entrench further harms. A community leader from Awach, where male-directed sexual violence was particularly widespread, confirmed that "the rape is the first part of the violation from which they suffer, but the silence and not being able to talk also makes them suffer in isolation, even up to now." Reflecting the lived realities of Acholi male survivors of sexual violence, transitional justice scholar Frank Haldemann (2009) theorizes that by "silencing the victims, their personal and social grievances have no reality. Thus, one's suffering is reduced to a clandestine experience-overlooked and forgotten. This ... adds to injury, and one can describe its devastating effects as 'the wounds of silence"' (693). Various male survivors therefore emphasized that "we need our violations to be recognized." Edström, Dolan, et al. (2016) similarly quote a male survivor who "would wish that the issues of sexual violence against men be recognized in the entire world" (31). According to the survivors from northern Uganda, recognizing sexual violence against men and survivors' experiences necessitates breaking 
the silence surrounding these crimes. "If we keep the silence, we cannot move forward," one male survivor stated, as others vehemently agreed. The Men of Courage chairperson similarly emphasized the need for breaking the silence: "What we need is to open up, share our stories and create awareness. We must reach out to all powers that everyone can be a victim of SGBV" (RLP 2014: 6).

During the workshops it also became evident that for the survivors, "being in a group is a way to break the silence" in the public sphere and on a societal level. As outlined by the Men of Courage chairperson, the groups" "aims and objectives are to break the silence." Thereby survivors' groups imply the potential to initiate a procedural transition from silence to recognition. Arguing along those lines, during the sixth Institute for African Transitional Justice (IATJ) in June 2016, RLP director Chris Dolan emphasized the need to consider transitions from silence to acknowledgment as a microlevel form of dealing with the past. In this reading, male survivors' groups can initiate a transformation from vulnerability to agency, and by association also a process of attaining justice-as explored below.

According to the survivors, the groups' engagement in advocacy is thus expected to contribute to breaking the silence on a societal level and to some degree even nationally and internationally. The groups thereby enable and catalyze individual members to exercise various forms of political agency in different spheres to obtain a sense of recognition of their experiences. For instance, individual members have participated in meetings and forums like the South-South Institute or IATJ to raise awareness about male survivors' experiences and to advocate for their demands. As described above, survivors like Okwera have narrated their testimonies in different geopolitical contexts, ranging from Cambodia to Uganda's capital, Kampala, to regional spaces such as Gulu or Kitgum town in Acholiland-thereby attaining recognition in different spaces and spheres as well as from different audiences.

However, these meetings and gatherings are primarily attended by professionals or selected NGO or government representatives, but generally not by community members, with only occasional exceptions. Therefore, and in close cooperation with RLP, selected members have participated in community screenings of RLP-produced documentaries about sexual violence against men to raise awareness and break the silence among the community. For instance, in May 2016, a video screening of the 2011 documentary They Slept with Me in Amuru district was attended by approximately five hundred community members, which was an unexpectedly high turnout. The Men of Courage chairperson, whose narrative is featured in the documentary, was present at the screening and afterwards engaged in a discussion with community members.

Overall, however, and despite the groups' objectives of breaking the silence, sexual violence against men and male survivors' experiences continue to be marginalized and silenced on a societal level, by external actors, and in official discourses and local accounts of the conflict alike. According to survivors themselves, 
therefore, more and continuous work is needed to obtain societal recognition of their harmful experiences.

Nevertheless, one must not uncritically assume a linear process of recognition that is expected to come from "speaking out" and "breaking the silence." Empirically, "speaking out" and obtaining recognition are rarely unitary and coherent processes. Although acknowledgment and recognition are often assumed to be straightforward consequences of testifying, in reality such processes are much more complex and can involve unintended and potentially harmful consequences. Inspired by anthropologist Fiona Ross, I therefore refrain from "assuming an unproblematic link between 'voice' and 'dignity' and between 'voice' and 'being heard"' (2003: 327) and ultimately recognition. As Hamber and Wilson write in reference to the South African Truth and Reconciliation Commission, "It should not be assumed too easily . . . that 'Revealing is Healing"' (2003: 37). Simply speaking about these violations and experiences can thus not be expected to translate automatically into recognition and can likewise not be assumed to be a universally healing, redemptive, and liberating exercise. Rather, and as argued by Hayes (1998), what fundamentally matters is "how we reveal, the context of the revealing, what it is that we are revealing" (43), and how the revealed content is received and responded to.

At the same time, and specifically applied to the situation of male sexual violence survivors in northern Uganda's hetero-patriarchal context, publicly speaking out about their harmful experiences of sexual abuse can have unintended consequences. Male survivors often do not want their families or communities to know what happened to them, thereby indicating important spatial nuances with regard to where and by whom recognition is to be obtained. These geographical dimensions are illustrated through the case study of Okidi referred to above, who has sought wider recognition of his experience by publishing his account in an online newspaper. In his home village and even within his family, however, nobody knows about his experience. This example illuminates the ambivalent situation of survivors seeking recognition of their experiences on a societal level but not within their own communities or by their families. Speaking out as part of an intended therapeutic process thus implies the potential danger of having these shameful and degrading experiences (semi)publicly known, not only abstractly or confined to the groups, but also locally, which can risk further social stigmatization and exclusion. Likewise, although the motivation to speak about their experiences applies to various survivors who seek societal recognition, this cannot generally be applied to all members of the groups.

Survivors' incentives to speak up about their experience and therefore to break the silence also often only seem feasible and desirable in the contemporary postconflict context. Many survivors emphasized that they are only hoping to obtain recognition now, for some of them thirty years after the violations occurred. While the conflict was ongoing and in the immediate aftermath of the 2006-2008 Juba Peace Talks, "the silence surrounding these crimes has also been protective," as one 
survivor put it. As noted by Erin Baines (2016), "Silence is often a strategy of survival in violent times, and enables those threatened to navigate difficult situations to protect themselves and loved ones" (19), illustrating that preserving silence can also be a way of exercising agency (which also applies to the case study of Okidi). In relation to these temporal nuances of recognition, it is helpful to refer to anthropologist Veena Das, who reminds us of the "difference between the time of occurrence and the time of telling, sometimes conceptualized as the difference between historical truth and narrative truth" (2007: 96). For sexual violence against men in Acholiland, this difference between the time of occurrence (1986-1992) and the time of telling (2011-present) is particularly striking.

\section{"BEING IN A GROUP IS ALSO ONE SENSE OF JUSTICE"}

To transition from this chapter to the next-focused on justice, recognition, and reparations-I conclude by teasing out how through their agentive capacities, groups also immediately link to questions of justice. By enabling survivors to engage with their experiences on their own terms and by addressing male sexual harms in myriad ways, survivors' groups also constitute a pathway, or a conduit, through which a sense of justice can be achieved among survivors and on the microlevel. In the absence of official, top-down, and state-administered justice avenues, groups thus constitute "alternatives to traditional institutional responses for harms that have too often gone unrecognized, unnamed and unaddressed" (Minow 1998: 4).

The vast majority of survivors who participated in this study indeed expressed that for them, "justice can be seen in a group like this." One survivor specifically said that "being in a group has been helpful to us ... so that we can get the justice that we wanted and deserve." As emphasized by yet another male survivor, being in a support group "is one sense of justice in a way that we now are together and we are seen and recognized as those people who underwent the specific kind of atrocities, but we are together." Several service providers working with male sexual violence survivors similarly confirmed that "being in a group can be a sense of justice for most of the survivors" and that "coming together in a group is also about attaining justice at their level." In considering survivors' groups as a pathway to justice, I follow Baines's (2010) approach to justice as "a social project" that "include $[s]$ the various strategies employed by the war-affected population to deal with the legacies of mass violence" (7). This broadened understanding of justice is laid out and conceptualized in greater detail in the following chapter.

In many ways, the group's potential to renegotiate survivors' identities and to repair broken relationships is underpinned by restorative conceptions of justice. For instance, one of the survivors emphasized that "justice for us means reestablishing relationships, among us and with families and communities," while a key informant working with survivors similarly explained that one of the 
major justice-related concerns for male survivors is to "restore trust and rebuild relationships that were damaged because of the rape" and that the "groups can help with that." Although primarily employed to deal with the restoration of relationships between victims and perpetrators, and only to a lesser extent also between survivors and communities, restorative justice theories offer important conceptual insights to understand how the rebuilding of relationships in this context can link to justice. Restorative justice theories are primarily about addressing "the range of harms that violence causes to human relationships and ... [restoring] relationships out of these variegated harms" (Llewellyn and Philpott 2014: 4), assuming human connections and relations, which survivors seek to rebuild, as "a starting point for thinking about what justice means" (ibid.). A restorative-relational conception of justice thus seeks to remedy the range of harms that violence and injustices can cause to human relationships.

In relation to "the struggle for recognition," survivors similarly emphasized that "justice is recognizing suffering" and that "for justice, we need our violations to be recognized." To conceptualize these linkages between recognition, agency, and voice, a recognition-theoretical understanding of justice as defined by Axel Honneth (1995) and as specifically applied to transitional justice processes by Frank Haldemann (2009) offer crucial theoretical insights. ${ }^{6}$ According to this conception, violence, humiliation, and injustice can be measured as the absence or denial of recognition. Responding to and reversing this misrecognition and humiliation, in turn, requires due acknowledgement of survivors as human selves and of their harmful experiences. Haldemann specifically applies these conceptual linkages between recognition and justice to processes of dealing with the past, asserting that "giving public recognition to the injured and their sense of injustice should be one of the central concerns to transitional justice" (2009: 737).

While previous research examined how victims' associations enable their members to engage with external processes of dealing with the past, the potential for survivors to experience justice through their participation in groups themselves has been insufficiently explored. Such an interrogation of the peripheries or margins of transitional justice processes thus has important implications for our understanding of justice in transition, requiring us to think outside the standardized toolbox of possible justice mechanisms. Justice as approached here, and as conceptualized more fully in the following chapter, is not primarily about ensuring or protecting rights in accordance with rights-based liberalism; instead it is about responding to harms by way of renegotiating impacted identities, restoring broken relationships, and obtaining recognition in noninstitutionalized settings and among survivors themselves. Technocratic and prescriptive measures are often ill equipped to achieve these relational and social components of agency and justice and are often unavailable or inaccessible for conflict-affected communities. Such is certainly the case for male survivors of sexual violence in northern Uganda. This necessitates a broadened and widened conceptualization of justice, beyond 
legalistic and institutionalized measures (chapter 6), as well as a survivor-centric approach (chapter 7 ).

These findings about survivors' groups as an avenue for justice thereby also support Martin's (2016) assessment that "justice is not something that happens to or for post-conflict societies, but [that] individuals employ their own agency in facilitating these processes" (414). Lundy and McGovern (2008) likewise emphasize that "there is a need to foster agency by thinking imaginatively outside the 'prevailing transitional justice box," adding that "the first step to developing strategies is to create spaces for people to determine, shape and develop solutions for themselves" (292). Tapping into these larger debates about participatory and alternative avenues of attaining justice, I have sought to show how survivors' groups can foster agency and thereby create spaces for survivors to develop strategies for and by themselves-in line with a victim-centric approach of dealing with the legacies of wartime sexual violence.

By enabling survivors to engage with their experiences and by immediately addressing survivors' gendered harms, the groups therefore embody the metaphorical "short stick" (see the introduction), which emphasizes the importance of being close to the "problem"-which in this case are survivors' sexual and gendered harms - in order to contribute to a solution, which the groups certainly do in numerous ways.

\section{CONCLUSION}

Although groups can thus provide avenues for survivors to exercise political agency, and thereby also facilitate justice on a microlevel—which primarily focuses on survivors' needs and is concerned with relationships between individualsadditional justice-related needs on the macrolevel nevertheless prevail. As articulated by one survivor, "Groups are one way for us to get justice, but in the future other measures are also needed." In this reading, survivors' groups can be seen as one piece within a larger and procedural puzzle of justice, further necessitating different components of redress, recognition, and reparations-which constitute the focus of the next chapter. 